\title{
Myocarditis Associated with Venlafaxine Overdose and Role of CYP2D6
}

Sofia Kaddaf*, Mohammed Amine Ktiri, Nadif Mariam, Adolphe Kasango, Yann Rosamel, Pascal Goube

Sud Francilien Hospital, Cardiology Unit, Corbeil-Essonnes, France

DOI: $10.36347 /$ sjmcr.2020.v08i10.003

| Received: 21.09.2020 | Accepted: 29.09.2020 | Published: 06.10.2020

*Corresponding author: Sofia Kaddaf

Abstract

Introduction: Venlafaxine is a serotonin-norepinephrine reuptake inhibitor used as an antidepressant that causes usually a mild cardiotoxicity when ingested in overdose. We report a case of a patient who developed rhabdomyolysis and acute heart failure with LV thrombus attributed to venlafaxine overdose. After venlafaxine discontinuation, there was rapid improvement, with regression of the radiological abnormalities and normalization of the LVEF. Case report: A 21-year-old man was admitted to the intensive care for acute renal failure secondary to rhabdomyolysis $(\mathrm{CPK}>140000 \mathrm{UI} / \mathrm{L}) 7$ hours after the ingestion of an $11 \mathrm{~g}$ of VENLAFLAXINE, complicated by acute pulmonary edema with acute respiratory distress. The electrocardiogram showed $\mathrm{T}$ wave inversion in anterior leads, but normal QRS and QTc duration. Initial troponin T was $1005 \mu \mathrm{g} / \mathrm{L}$ BNP: $13045 \mathrm{pg} / \mathrm{ml}$.The patient developed severe acute pulmonary edema. The left ventricular shortening fraction was $56 \%$ on echocardiography with anteroseptal akinesis with a non-mobile round echodensity measuring $13 \times 9 \mathrm{~mm}$, consistent with an LV thrombus. The coronary arteries appear normal at coronary angiography. The patient was anuric and required continuous venovenous hemofiltration. Management consisted in noninvasive ventilation and dobutamine associated with intravenous isotonic saline, bicarbonate, and loop diuretics to control left ventricular dysfunction. Ventilator and cardiac support were maintained for 48 hours. Progressive improvement in respiratory failure was observed, and creatine kinase level decreased to 336 $\mathrm{U} / \mathrm{L}$ on day 4 , The patient was discharged from the intensive care unit on day 10, to Cardiology department with curative anticoagulation, Cardiac magnetic resonance imaging at Day 20 revealed edema of the anteroseptal walls on T2-weighted images and the T1 mapping, Furthermore, The anterospetal segment of the left ventricle was hypokinetic, and the echodensity structure was no longer visible in either a short-axis apical view or a 4-chamber view. The patient eventually was discharged from the hospital approximately 4 weeks after admission. Conclusions: The purpose of this case is to discuss the potential mechanisms of cardiotoxicity following VENLAFAXINE overdose and his reversiblity.

Keywords: Myocarditis, Venlafaxine toxicity, Serotonin-norepinephrine reuptake inhibitor (SNRI), Toxicology, Overdose.

Copyright @ 2020: This is an open-access article distributed under the terms of the Creative Commons Attribution license which permits unrestricted use, distribution, and reproduction in any medium for non-commercial use (NonCommercial, or CC-BY-NC) provided the original author and source are credited.

\section{INTRODUCTION}

Antidepressants are the most commonly prescribed drugs for psychiatric treatment, Venlafaxine a nontricyclic dual-acting serotonin-norepinephrine reuptake inhibitor and now the one of the most frequently prescribed antidepressants worldwide [1]. While there is acceptable cardiovascular safety with the use of selective serotonin reuptake inhibitors (SSRI), large overdoses of venlafaxine may lead to acute heart failure and eventually death [2].

\section{Case Report}

A 21-year-old man was admitted to the intensive care for acute renal failure secondary to rhabdomyolysis (CPK > $140000 \mathrm{UI} / \mathrm{L}) 7$ hours after the ingestion of an $11 \mathrm{~g}$ of VENLAFLAXINE, complicated by acute pulmonary edema with acute respiratory distress. The electrocardiogram showed $\mathrm{T}$ wave inversion in anterior leads, but normal QRS and QTc duration. Initial troponin T was $1005 \mu \mathrm{g} / \mathrm{L}$ BNP: 13045 $\mathrm{pg} / \mathrm{ml}$.The patient developed severe acute pulmonary edema. The left ventricular shortening fraction was $56 \%$ on echocardiography with anteroseptal akinesis with a non-mobile round echodensity measuring $13 \times 9 \mathrm{~mm}$. consistent with an LV thrombus. The coronary arteries appear normal at coronary angiography. The patient was anuric and required continuous venovenous hemofiltration. Management consisted in noninvasive ventilation and dobutamine associated with intravenous isotonic saline, bicarbonate, and loop diuretics to control left ventricular dysfunction. Ventilator and cardiac support were maintained for 48 hours. 
Progressive improvement in respiratory failure was observed, and creatine kinase level decreased to 336 $\mathrm{U} / \mathrm{L}$ on day 4.

The patient was discharged from the intensive care unit on day 10, to Cardiology department for anticoagulation, and a cardiac MRI was ordered. 20 days later, It revealed edema of the anteroseptal walls on T2-weighted images and the T1 mapping, Furthermore, The anterospetal segment of the left ventricle was hypokinetic, and the echodensity structure was no longer visible in either a short-axis apical view or a 4-chamber view. The patient eventually was discharged from the hospital approximately 4 weeks after admission.

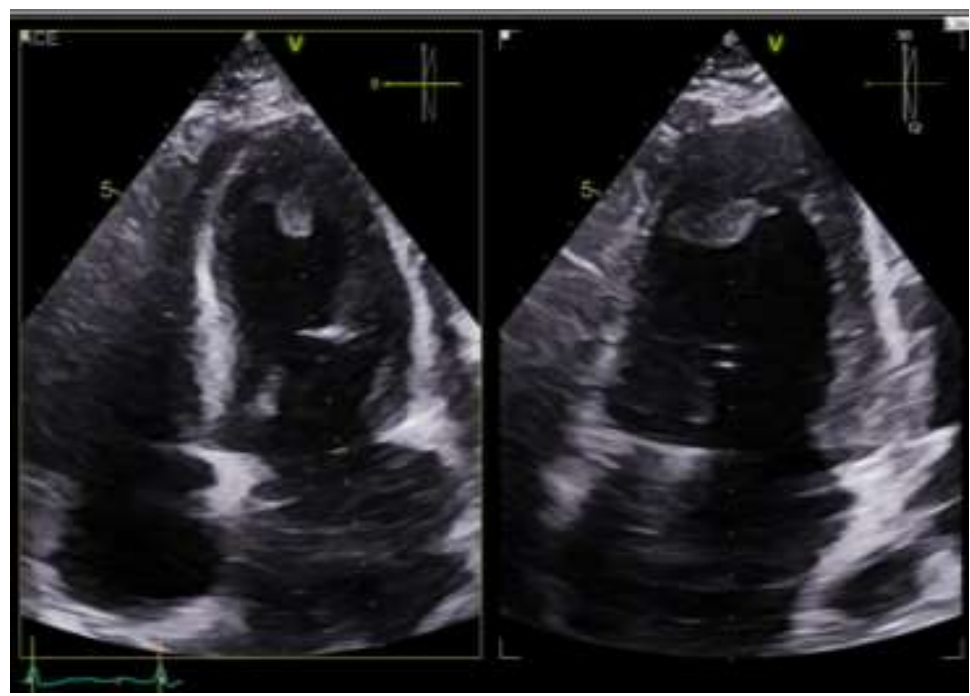

Fig-1: Echocardiography showing anteroseptal thrombus in a 4-2 chamber view

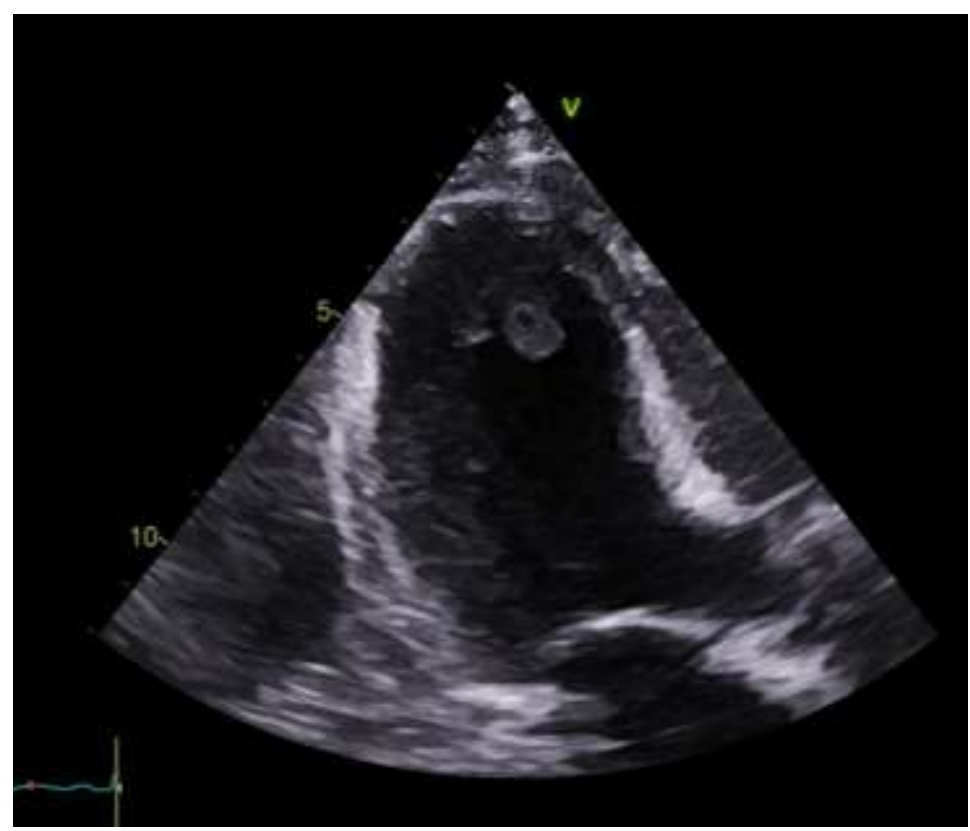

Fig-2: Echocardiography showing anterior thrombus in a 3 chamber view 


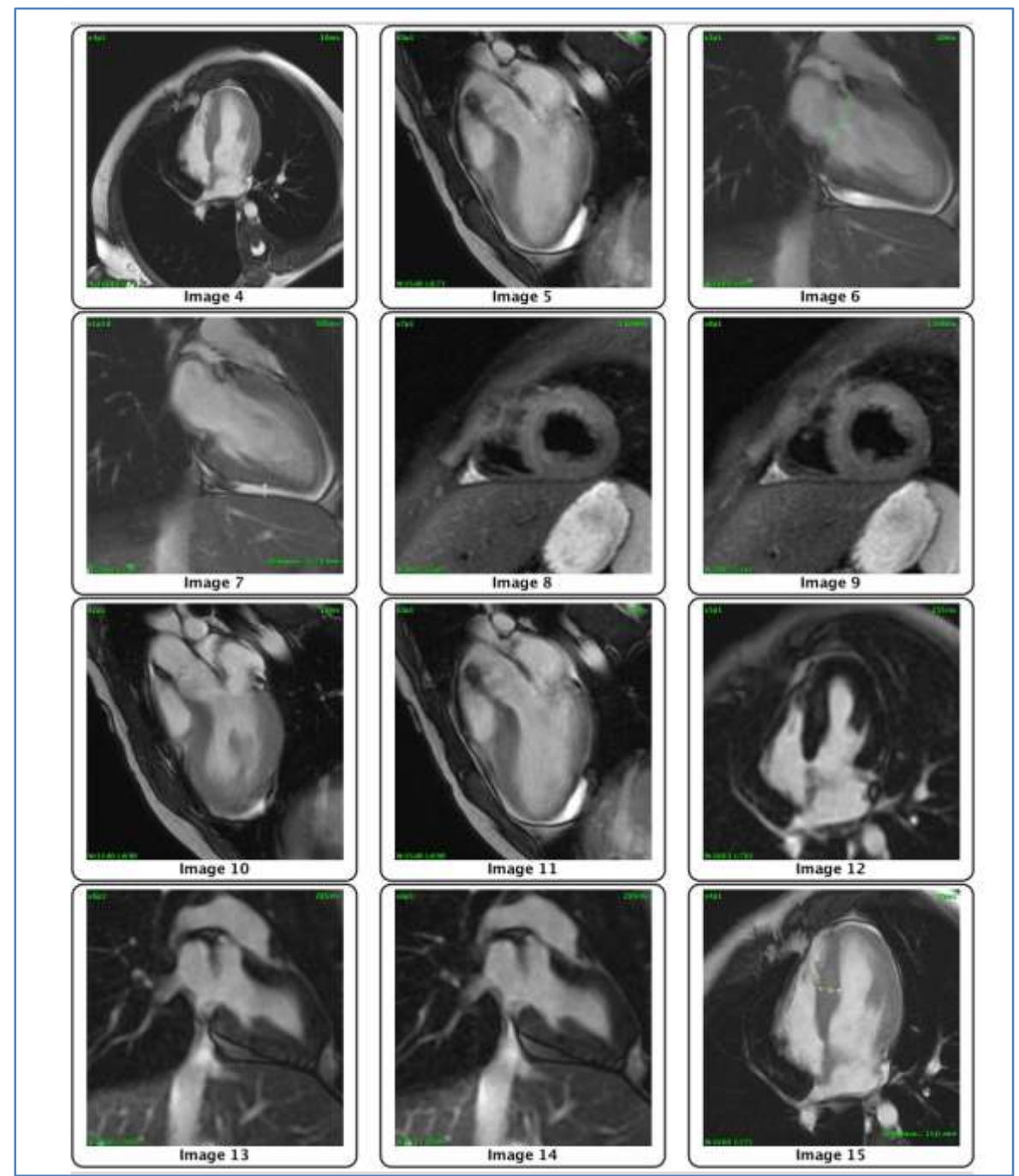

Fig-3: MRI cardiac showing edema of the anteroseptal walls on T2-weighted images and the T1 mapping

\section{DiscUSSION}

Venlafaxine is a bicyclic antidepressant that inhibits neuronal uptake of norepinephrine, serotonine, and, to a lesser extent, dopamine (2) that causes usually a mild cardiotoxicity when ingested in overdose.(6) This complication should be clearly differentiated from the effects on cardiac conduction illustrated by the widening of QRS complexes induced by inhibiting the inward sodium current (INa) (7) .Although, The mechanisms underlying venlafaxine-related myocarditis with preserved cardiac conduction function have been discussed, but not fully elucidated and he is still not fully understood. One of the most likely explanations may be a catecholamine-induced myocardial damage in conjunction with the inhibition of norepinephrine (and dopamine) reuptake. This mechanism has been suggested in the pathophysiology of "takotsubo" cardiomyopathy that has been occasionally observed with venlafaxine or other antidepressants [3, 4]. Another theory is the hypertrophic effects of dose-related sustained hypertension [2].
The alteration of LV function was usually severe and diffuse. No patient experienced serious cardiac arrhythmias. In the observation published by Caroselli et al., both echocardiographic and electrocardiographic findings a focal myocardial ischemia in the anterolateral territory with a normal coronary angiogram. After one month, the patient died and the autopsy was consistent with a focal myocardial wall rupture. Myocardial infarction with no stenosis coronary arteries has been reported in at least two recent publications (5) (6). One group of authors reported dilated cardiomyopathy and cardiogenic shock in a patient with previously normal heart function, with recovery of the LVEF after the discontinuation of the medication (8). The treatment of venlafaxine-related cardiac failure relies mainly on the administration of inotropic drugs. A possible role for CYP2D6 polymorphism has also been proposed. Several mechanisms have been proposed, including multivessel epicardial spasm or catecholamine-induced myocardial damage, as observed in neurogenically mediated myocardial stunning [9]. As venlafaxine is also a dopamine and norepinephrine reuptake inhibitor, 
patients with venlafaxine overdose might be at risk for Takotsubo cardiomyopathy.

In our case, there was no concomitant ingestion of other drugs with SRI activity. A local anteroseptal myocarditis with a thrombus, the exact mechanisms of myocardial dysfunction in SRI overdose remains unknown. In our patient, no cardiac conduction abnormalities suggestive of membrane-stabilizing activity occurred. Although the coronary arteries appear normal at coronarography.the absence of cardiovascular risk factors, troponin elevation, and inversion $\mathrm{T}$ wave on electrocardiogram, and systematization of the hypokinesia on echocardiography suggest that a large vessel coronary disease was likely in our patient but coronarography and MRI cardiac confirmed diagnostic of myocarditis.

Several case reports have shown an association between cardiomyopathy and a poor CYP2D6 metabolizer status in patients taking venlafaxine [10, $11]$.

\section{CONCLUSION}

Cardiotoxicity following venlafaxine overdose may be due to several pathophysiological mechanisms. A large overdose of venlafaxine seems necessary to induce acute LV failure, also great variations in interindividual susceptibility interestingly, acute heart failure at echocardiography, may be observed in the absence of any severe intraventricular conduction abnormality.

\section{AbBREVIATIONS}

LVEF: left ventricular ejection fraction -BNP: B-type natriuretic peptide -CPK: creatine phosphokinase -

\section{REFERENCES}

1. Francesconi G, Orsolini L, Papanti D, Corkery JM, Schifano F. Venlafaxine as the 'baby ecstasy'? Literature overview and analysis of web-based misusers' experiences. Hum Psychopharmacol. 2015;30(4):255-261 .
2. M. BATISTA. The spectrum of acute heart failure after venlafaxine overdose, Clinical Toxicology Early Online. 2013, 51: 92-95

3. Christoph M, Ebner B, Stolte D, Ibrahim K, Kolschmann S, Strasser RH. Broken heart syndrome: Tako tsubo cardiomyopathy associated with an overdose of the serotonin-norpepinephrine reuptake inhibitor venlafaxine Eur Neuropsychopharmacol. 2010; 20: 594 - 597.

4. De Roock S, Beauloye C, De Bauwer I, Vancraynest D, Gurne O, Gerber B. Tako-tsubo syndrome following nortriptyline overdose . Clin Toxicol. 2008; 46: 475-478.

5. Caroselli C, Ricci G. The venlafaxine "heart revenge": a short report. Clin Cardiol. 2010; 33: e46-e47.

6. Godkar D, Stensby J, Sinnapunayagam S, Niranjan S. Venlafaxine induced acute myocardial infarction with normal coronary arteries. Am J Ther. 2009; 16: 365-366 .

7. Khalifa M, Daleau P, Turgeon J. Mechanism of sodium channel block by venlafaxine in guinea pig ventricular myocytes. J Pharmacol Exp Ther. 1999; 291: $280-284$

8. Charniot JC, Vignat N, Monsuez JJ, Kidouche R, Avramova B, Artigou JY. Cardiogenic shock associated with reversible dilated cardiomyopathy during therapy with regular doses of venlafaxine. Am J Emerg Med. 2010;28(2):256.e1-5.

9. Bybee KA, Kara T, Prasad A. Transient left ventricular apicalballooning: a syndrome that mimics ST-segment elevation myocardial infarction. Ann Intern Med. 2004; 141:858 - 65.

10. Chua EW, Foulds J, Miller AL, Kennedy MA. Novel CYP2D6 and CYP2C19 variants identified in a patient with adverse reactions towards venlafaxine monotherapy and dual therapy with nortriptyline and fluoxetine. Pharmacogenet. Genomics.2013; 23(9), 494-497.

11. Vinetti M, Haufroid V, Capron A, Classen JF, Marchandise S, Hantson P. Severe acute cardiomyopathy associated with venlafaxine overdose and possible role of CYP2D6 and CYP2C19 polymorphisms. Clin. Toxicol. 2011; 49(9), 865-869. 